\title{
A (not so) dangerous method: pXRF vs. EPMA-WDS analyses of copper-based artefacts
}

\author{
V. Orfanou • Th. Rehren
}

Received: 12 March 2014 / Accepted: 30 May 2014 / Published online: 13 June 2014

(C) The Author(s) 2014. This article is published with open access at Springerlink.com

\begin{abstract}
Analysis of metal objects with portable and handheld X-ray fluorescence spectrometry has become increasingly popular in recent years. Here, methodological concerns that apply to non-destructive, surface examination with XRF instruments of ancient metal artefacts are discussed based on the comparative analyses of a set of copper-based objects by means of portable X-ray fluorescence (pXRF) and electron probe microanalyser (EPMA). The analytical investigation aims to explore issues of instrument comparability and reliability of the non-invasive $\mathrm{pXRF}$ results. The different analytical approaches produce a comparable pattern for the major element concentrations, but substantial variation is evident when it comes to the absolute values for major and minor/trace elements.
\end{abstract}

Keywords X-ray fluorescence spectrometry · Electron probe microanalyser $\cdot$ Museum artefacts $\cdot$ Copper-alloys

\section{Introduction}

Starting point for this study was the ever-increasing use of portable X-ray fluorescence (pXRF) in archaeology due to its non-destructive, non-invasive character and the possibility of in situ examination of both artefacts and structures, as well as its low cost compared to other means of analysis. Surface, non-invasive analytical techniques are often favoured and preferred by archaeologists and curators who often directly correlate 'archaeometric analysis' with 'object deformation'. All the above make pXRF instruments the most preferable

V. Orfanou $(\bowtie)$

UCL Institute of Archaeology, London, UK

e-mail: s.orfanou@ucl.ac.uk

Th. Rehren

UCL Qatar, Education City, Doha, Qatar

e-mail: th.rehren@ucl.ac.uk choice for archaeologists, curators and conservators alike (Tite et al. 2002; Henderson and Manti 2008; Cesareo et al. 2011; Martinón-Torres et al. 2012). A growing number of researchers gain access to and use both handheld and labbased pXRF equipment for the archaeometric study of metal artefacts which highlights the importance of this and similar comparative studies (Angelini et al. 2006; Kantarelou et al. 2007; Karydas 2007; Dussubieux et al. 2008; Shugar and Mass 2012; Shugar 2013; Charalambous et al. 2014).

A group of copper-based objects has been selected for comparative analysis in order to address issues of the comparability of analytical results and their possible effect on the archaeological interpretation of ancient copper alloys. The corrosion effect on the objects' surfaces, and the potentials and limitations of the different analytical techniques and methodological strategies applied that would affect any analytical results were also taken into consideration. For this, a portable, labbased XRF spectrometer ( $\mathrm{pXRF}$ ) and an electron probe microanalyser with an attached wavelength-dispersive spectrometer (EPMA-WDS) were used to analyse the same samples. The main aim of the present study was to explore the relationship between non-invasive, surface (lab-based pXRF) and quantitative invasive (EPMA) analyses on sound metal from the objects' core using metallographic cross sections, in order to provide an evaluation of the reliability of surface $\mathrm{pXRF}$ data on excavated copper-based artefacts. As such, it is intended to identify trends and patterns in the results and to highlight the particular characteristics of the two instruments that could affect archaeological interpretations of metal object assemblages.

\section{Methodology}

A sample of 41 small copper-based objects has been examined qualitatively by pXRF and quantitatively by EPMA. All artefacts are part of the Archaeological Museum of Volos 
collection and have been found at the sanctuary of Enodia and Thavlios Zeus at ancient Pherae in Thessaly, Greece; they largely date to the Protogeometric, Geometric and early Archaic periods, that is the first half of the first millennium B.C. (Béquignon 1937; Kilian 1975; Kilian-Dirlmeier 1985; Vokotopoulou 1986, 1990; Bouzek 1997). Sampling criteria primarily focused on the preservation of a substantial metallic core as well as the possibility of obtaining a cut sample in addition to the surface analysis, such as from already fragmented objects. Even though no particular distinction was made in regard to the typology and/or use of the artefacts, mainly articles of personal adornment are represented in the sample such as fibulae and pins, arm bands, sheets, rings and spirals (Table 1).

The assemblage presented here was analysed using three different protocols in order to better understand the nature of the quality of surface XRF analysis as they can be obtained in real-world conditions when analysing archaeological collections of copper-based artefacts. The first protocol included EPMA-WDS (core metal) analysis, the other two lab-based pXRF (substrate metal layer on a cleaned surface and the intact corroded surface). Thus, XRF1 reports data obtained on a cleaned area using established conservation methods to reveal a visually metallic surface, while XRF2 reports data on the corroded surface.

The investigation of the samples' microstructure was conducted with reflected light (Olympus BX60 with an attached digital camera) and scanning electron microscopy (Hitachi S3400N); the results are used here only for illustrative purposes. The emphasis of this study lies on the comparison of two analytical instruments (pXRF and EPMA) employed for the quantitative examination of the sample. The instruments are both commonly used and present different features that would immediately affect the quality of the data provided, such as different detection limits, area vs. spot measurements and the potential for analysing different parts of the object, i.e. the corroded surface, the substrate, defined here as the partly corroded layer immediately beneath the original surface, and the core metal (Fig. 1).

During quantitative analysis with both instruments, a set of nine elements was analysed, namely, $\mathrm{Cu}, \mathrm{Sn}, \mathrm{Pb}, \mathrm{Fe}, \mathrm{As}, \mathrm{Zn}$, $\mathrm{Sb}, \mathrm{Mn}$ and $\mathrm{Ni}$ (note that $\mathrm{Mn}$ was not analysed during XRF1;

Table 1 Object type and frequency in the sample

\begin{tabular}{lll}
\hline Description & Count & Count (\%) \\
\hline Rings & 17 & 41 \\
Sheets & 10 & 24 \\
Fibulae & 7 & 17 \\
Arm bands & 2 & 5 \\
Pins & 2 & 5 \\
Spirals & 3 & 7 \\
Total & 41 & 100 \\
\hline
\end{tabular}

the EPMA analysis of sound metal also included oxygen. This was found in rather low levels as expected for the examination of sound metal and thus is not reported here). Cut samples have been mounted in epoxy resin blocks and then polished using standard procedures down to $0.25 \mu \mathrm{m}$ using diamond paste. Quantitative analyses were conducted with an EPMAWDS (JXA-8100 Electron Probe Microanalyser) at the Wolfson Archaeological Science Laboratories, UCL Institute of Archaeology, London. Pure elements have been used to calibrate the instrument with the exception of arsenic for which an indium arsenide compound was used, while its performance was monitored by the analyses of two certified reference materials (CRMs), namely, brass 42.23.2 and leaded bronze 50.04.4 (Bureau of Analysed Samples Ltd.; Table 2). Depending on the nature of each sample, multiple area and spot measurements were taken in magnifications of $1,000 \times$ at a working distance of $11 \mathrm{~mm}$ with an acceleration voltage of $20 \mathrm{kV}$ and a beam current of $50 \mathrm{nA}$. The data reported here for each sample is the average of those individual measurements. The standard deviation of those multiple analyses is reported for the reference materials (Table 2) to illustrate the analytical precision of the instrument.

Non-invasive XRF analyses took place at the Metal Conservation Laboratory of the 13th Ephorate for Prehistoric and Classical Antiquity (EPCA) in Volos, Greece, using a portable, though not handheld, ED-XRF spectrometer developed at the Institute of Nuclear Physics, NCSR Demokritos (Fig. 2). The XRF spectrometer consisted of an Rh-anode side-window, low power X-ray tube $(50 \mathrm{~W}, 40 \mathrm{kV}, 125 \mu \mathrm{m}$ Be window), a PIN X-ray detector and a multichannel analyser (MCA) card. The analytical range of this portable $\mathrm{XRF}$ spectrometer extends from $Z=14$ (silicon) up to $Z=92$ (uranium). The device can operate under two distinct

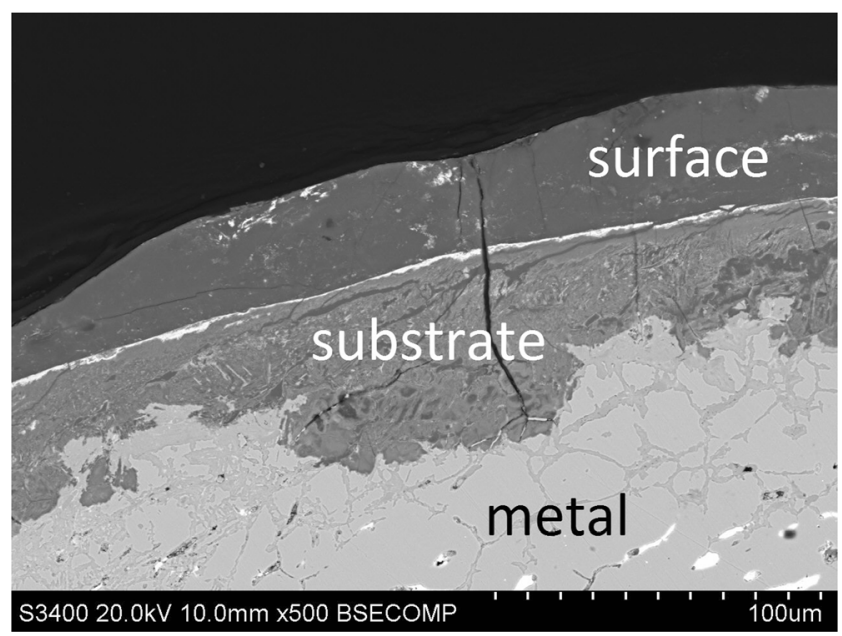

Fig. 1 Backscatter scanning electron image of ring AE 34 showing corrosion of the substrate (mid-grey) and the surface (dark grey) of the object, separated by a thin lead-rich corrosion layer (white line) which also marks the original surface. Bright white areas in the lower left part of the metal are lead inclusions. 
Table 2 Summary of brass and leaded bronze standards analysed with EPMA

\begin{tabular}{|c|c|c|c|c|c|c|c|c|c|c|c|}
\hline & $\mathrm{Zn}$ & As & $\mathrm{Fe}$ & $\mathrm{Cu}$ & $\mathrm{S}$ & $\mathrm{Sn}$ & $\mathrm{Bi}$ & $\mathrm{Sb}$ & $\mathrm{Ni}$ & $\mathrm{Mn}$ & $\mathrm{Pb}$ \\
\hline \multicolumn{12}{|l|}{42.23 .2 brass } \\
\hline Mean $(n=8)$ & 22.47 & 0.19 & 0.35 & 73.23 & 0.05 & 1.66 & 0.02 & 0.39 & 0.18 & 0.02 & 0.63 \\
\hline$\sigma$ & 0.08 & 0.03 & 0.03 & 0.56 & 0.01 & 0.11 & 0.02 & 0.06 & 0.01 & 0.00 & 0.21 \\
\hline CV (\%) & 0.38 & 13.51 & 7.92 & 0.77 & 22.73 & 6.87 & 86.89 & 14.77 & 4.83 & 18.04 & 33.38 \\
\hline CRM & 22.13 & 0.17 & 0.35 & 74.36 & 0.05 & 1.63 & 0.03 & 0.36 & 0.17 & 0.02 & 0.58 \\
\hline$\delta$ abs & -0.34 & -0.02 & 0.001 & 1.13 & -0.01 & -0.03 & 0.01 & -0.03 & -0.01 & 0.00 & -0.06 \\
\hline$\delta$ rel $(\%)$ & -1.53 & -10.86 & 0.25 & 1.52 & -14.72 & -1.87 & 43.75 & -9.23 & -8.33 & 2.63 & -10.24 \\
\hline \multicolumn{12}{|c|}{50.04 .4 leaded bronze } \\
\hline Mean $(n=10)$ & 0.66 & 0.06 & 0.13 & 76.53 & 0.17 & 11.02 & 0.10 & 0.53 & 1.18 & 0.04 & 9.07 \\
\hline$\sigma$ & 0.05 & 0.02 & 0.01 & 2.60 & 0.05 & 0.49 & 0.05 & 0.04 & 0.05 & 0.01 & 2.94 \\
\hline CV (\%) & 8.25 & 42.78 & 4.95 & 3.40 & 27.33 & 4.41 & 43.68 & 8.13 & 3.96 & 28.33 & 32.43 \\
\hline CRM & 0.66 & 0.06 & 0.10 & 76.11 & 0.14 & 11.30 & 0.10 & 0.50 & 1.10 & 0.03 & 9.94 \\
\hline$\delta$ abs & 0.00 & 0.00 & -0.03 & -0.42 & -0.03 & 0.28 & 0.00 & -0.03 & -0.08 & -0.01 & 0.87 \\
\hline$\delta$ rel (\%) & -0.55 & 6.67 & -31.30 & -0.55 & -22.43 & 2.46 & -3.30 & -6.38 & -7.57 & -43.57 & 8.76 \\
\hline
\end{tabular}

conditions: one unfiltered mode with the voltage set at $15 \mathrm{kV}$ and a filtered one with the voltage set at $40 \mathrm{kV}$; we used the latter for the analyses presented here. Two laser pointers are mounted in the spectrometer head in such a way that the intersection point of their beams coincides with the crosspoint of the incident X-ray beam axis and the detector axis. The beam spot at the sample position has a diameter of less than $2 \mathrm{~mm}$. The spectrometer head is attached in an X-Y-Z position, allowing its easy movement in the $X-Y$ directions (for more details on the XRF technique, see also Karydas 2007)

Measurements were taken both on the objects' intact corroded surface ('XRF2') as well as on an area scraped clean where the metal substrate with its characteristic shine was revealed ('XRF1'). For each analysis, i.e. XRF1 and XRF2, two spot measurements of $300 \mathrm{~s}$ at 2,048 channels were taken per sample at an acceleration voltage of $40 \mathrm{kV}$ and a beam current of $30 \mu \mathrm{A}$. Taking into consideration issues of ancient metal heterogeneity caused either during manufacture or by post-depositional oxidation (Caley 1964; Charles 1973, p. 105), spot measurements of $2 \mathrm{~mm}$ were taken in two different areas on the surface of each sample in order to obtain more representative chemical compositions. Finally, a set of CRMs was regularly analysed to test the XRF's stability, accuracy and precision, namely, no. 691 of the European Commission, Community Bureau of Reference (BCR; Table 3).

Both instruments' performance was found to be stable over the duration of the study; accuracy and precision levels were repeatedly found satisfactory with a coefficient of variation (CV) for bronze (BCR 961) analysed with pXRF of $0.5 \%$ for $\mathrm{Cu}$ and $6.2 \%$ for $\mathrm{Sn}$, and $\delta$ relative of 0.03 and $1.53 \%$ for $\mathrm{Cu}$ and $\mathrm{Sn}$, respectively. Both instruments have broadly similar levels of accuracy and precision when analysing the CRMs, with EPMA regularly having the edge over pXRF.
Nonetheless, different minimum detection limits (MDL) are reported for the two instruments. Thus, MDL for the EPMA is reported at approximately $100 \mathrm{ppm}$, whereas a realistic MDL for the XRF would be placed at $0.1 \%$. All the same, lower accuracy levels on the whole are expected for such low concentrations.

XRF1 and XRF2 methodologies were followed in order to monitor changes that take place on the objects' surface during burial as a result of endogenous (e.g. the nature of the alloy) and exogenous corrosion processes, i.e. the objectenvironment interaction, and the way these may affect element concentration as measured on the substrate and on the intact surface including patina and other growth corrosion layers (Scott 1985, 2002; Franceschi et al. 1998; Ingo et al. 2006; p. 518; Mezzi et al. 2012, p. 953). This comparison allowed testing the degree to which surface XRF analysis is representative of the metal's composition prior to final deposition and

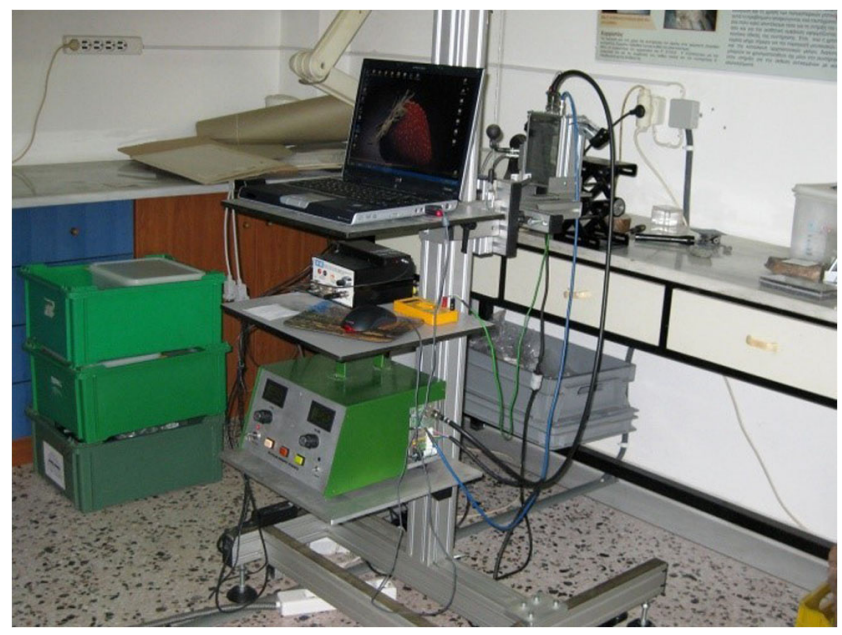

Fig. 2 The portable XRF instrument used for the surface, non-invasive analysis 
Table 3 Analysis of the four CRM BCR-691 discs during examination of the material with the $\mathrm{pXRF}$

\begin{tabular}{|c|c|c|c|c|c|c|}
\hline \multicolumn{2}{|c|}{ BCR-691 disc } & \multirow[t]{2}{*}{$\% \mathrm{Cu}$} & \multirow[t]{2}{*}{$\% \mathrm{Zn}$} & \multirow[t]{2}{*}{$\%$ As } & \multirow[t]{2}{*}{$\% \mathrm{Sn}$} & \multirow[t]{2}{*}{$\% \mathrm{~Pb}$} \\
\hline A & Leaded bronze & & & & & \\
\hline \multirow[t]{3}{*}{ Analysed } & Mean $(n=11)$ & 77.08 & 5.62 & 0.18 & 6.26 & 10.86 \\
\hline & $\sigma$ & 0.93 & 0.33 & 0.03 & 0.42 & 0.92 \\
\hline & CV $(\%)$ & 1.20 & 5.82 & 14.70 & 6.64 & 8.51 \\
\hline \multirow[t]{3}{*}{ Certified } & BCR & 78.73 & 6.02 & 0.19 & 7.16 & 7.90 \\
\hline & $\delta$ abs & 1.65 & 0.40 & 0.01 & 0.90 & 2.96 \\
\hline & $\delta$ rel (\%) & 2.10 & 6.67 & 7.03 & 12.53 & 37.51 \\
\hline B & Brass & & & & & \\
\hline \multirow[t]{3}{*}{ Analysed } & Mean $(n=9)$ & 84.08 & 13.33 & 0.23 & 2.00 & 0.36 \\
\hline & $\sigma$ & 0.61 & 0.54 & 0.01 & 0.23 & 0.13 \\
\hline & CV $(\%)$ & 0.73 & 4.06 & 6.02 & 11.63 & 36.90 \\
\hline \multirow[t]{3}{*}{ Certified } & $\mathrm{BCR}$ & 82.65 & 14.80 & 0.10 & 2.06 & 0.39 \\
\hline & $\delta$ abs & 1.43 & 1.47 & 0.13 & 0.06 & 0.03 \\
\hline & $\delta$ rel (\%) & 1.73 & 9.94 & 135.24 & 2.99 & 8.12 \\
\hline $\mathrm{D}$ & Leaded bronze & & & & & \\
\hline \multirow[t]{3}{*}{ Analysed } & Mean $(n=9)$ & 76.48 & 0.34 & 0.22 & 8.08 & 14.88 \\
\hline & $\sigma$ & 0.52 & 0.06 & 0.06 & 0.63 & 0.85 \\
\hline & CV $(\%)$ & 0.68 & 17.26 & 28.55 & 7.83 & 5.74 \\
\hline \multirow[t]{3}{*}{ Certified } & $\mathrm{BCR}$ & 80.27 & 0.15 & 0.29 & 10.10 & 9.20 \\
\hline & $\delta$ abs & 3.79 & 0.19 & 0.07 & 2.02 & 5.68 \\
\hline & $\delta$ rel (\%) & 4.72 & 128.38 & 23.35 & 19.98 & 61.76 \\
\hline E & Bronze & & & & & \\
\hline \multirow[t]{3}{*}{ Analysed } & Mean $(n=9)$ & 92.42 & 0.41 & 0.20 & 6.89 & 0.08 \\
\hline & $\sigma$ & 0.45 & 0.04 & 0.03 & 0.43 & 0.07 \\
\hline & CV $(\%)$ & 0.49 & 8.92 & 13.70 & 6.22 & 81.31 \\
\hline \multirow[t]{3}{*}{ Certified } & BCR & 92.45 & 0.16 & 0.19 & 7.00 & 0.20 \\
\hline & $\delta$ abs & 0.02 & 0.25 & 0.01 & 0.11 & 0.12 \\
\hline & $\delta \operatorname{rel}(\%)$ & 0.03 & 158.67 & 3.32 & 1.53 & 60.68 \\
\hline
\end{tabular}

$\sigma$ standard deviation, $C V$ coefficient of variation, $n$ number of spot analyses

corrosion. At this point though, it is worth pointing out that removing growth corrosion layers from a bronze object's surface alone does not guarantee the removal of all corrosion products until sound metal is revealed since the survival of metal grains in a matrix rich in corrosion products (intergranular corrosion) occurs quite often (Scott 1985, pp. 50-51, 1991). Typically the substrate of metal artefacts is corroded to variable depths. Thus, in order to reveal the sound metal layers, part of the substrate was scraped away as well. In the case of bronzes, metal is mostly substituted by copper oxides, chlorides and carbonates, as well as pure copper, and the oxides of other metals such as tin, iron, lead, etc., as, for example, found in a group of Roman and Punic bronzes with very similar compositions to the Pherae assemblage (Scott 1985; Mezzi et al. 2012, p. 956).

Based on the assessment of the CRM data and the fact that the EPMA analyses were done on demonstrably sound metal in polished cross sections, while even the substrate $\mathrm{pXRF}$ data is likely to include some corrosion material, we take the EPMA data as the 'true' reference point for our subsequent comparison. On the basis of the results from the above CRMs analyses and the CV values, we assume that this data is accurate within a few percent of the real values for copper and tin, and within $10 \%$ of the absolute values for the minor elements such as lead or iron.

EPMA analysis and comparison with pXRF results allowed the evaluation of the efficiency and reliability of pXRF analyses of visually sound metal (XRF1). Since both (EPMA and XRF1) are analyses of sound metal areas from the same objects, a direct replication of their values would indicate the same level of accuracy of each instrument. Certain patterns and trends though that arise as a result of different instrument features such as detection limits or spot/area measurements result in a deviation of pXRF values from the more accurate EPMA ones. Additionally, variation in values could result from the heterogeneity of the metal core in relation to the substrate as well as from the various and complex degradation phenomena (Ingo et al. 2006). Overall, the above methodology was designed to provide a 'guide' for the interpretation of pXRF results on copper-based artefacts and the critical evaluation of the questions to be addressed when invasive, and thus, more accurate analysis is not available.

\section{Results}

Quantitative examination of the samples showed the presence of mainly bronze artefacts (here, the term 'bronze' is used to describe a binary $\mathrm{Cu}-\mathrm{Sn}$ alloy with additions of tin of more than $4 \% \mathrm{Sn}$ ) with fewer examples of unalloyed copper (mostly showing 98-99 \% Cu). A few leaded bronze samples are present in the sample, i.e. a ternary alloy with tin and lead in amounts to suggest their deliberate addition. Lead contents above $4 \%$ have been often used to identify its purposeful addition as opposed to impurity levels or the results of recycling operations (Tylecote et al. 1977; Pernicka et al. 1990, p. 272; Mangou and Ioannou 1998, p. 98). Here, five objects with $>4 \%$ lead (as analysed with EPMA) have been found, but only four of these stand out from the bulk of the sample pointing to deliberate additions of lead (Fig. 3). It seems that in this assemblage, the natural lead contents can reach up to $5 \mathrm{wt} \%$.

Certain trends can be seen for the three analytical approaches employed (EPMA, XRF1 and XRF2) particularly when looking at the distribution of individual elements. The occurrence of these characteristic patterns has to be attributed mainly to the analytical instrument properties when it comes to the comparison between EPMA and XRF1 results, and to corrosion effects as opposed to the analyses of sound metal, namely, EPMA/XRF1, and surface corrosion layers (XRF2). 


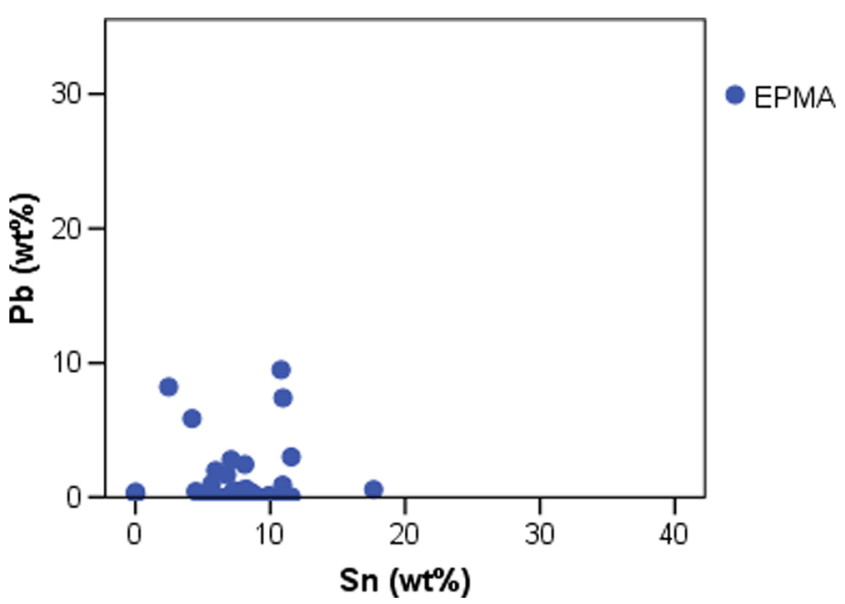

Fig. 3 Scatter plot of tin against lead values for the EPMA analyses

Major differences are seen for all analysed elements, with absolute differences most obvious for the two main compounds (reaching $13 \mathrm{wt} \%$ for copper and nearly $6 \mathrm{wt} \%$ for tin) but proportionately even bigger discrepancies for the minor elements (reaching a factor of 15 for iron). Below, we present and discuss the differences first between EPMA and XRF1 values, where we assume that the differences mostly reflect the different performance parameters of the instruments, with only some influence from corrosion. Following this, we compare XRF1 (visually sound metal) analyses to XRF2 (corroded surfaces) analyses to explore the effect of corrosion on the analytical results.

\section{Comparison EPMA-pXRF}

The nominally largest differences between EPMA and XRF1 results are with copper (3.7\% difference) and tin (1.3\%; Table 4). In relative terms, however, the discrepancy between the two copper values is less than $5 \%$ of the absolute value, a level of agreement or accuracy often accepted for routine analyses [see, e.g. Hein et al. (2002) for a more detailed discussion of the levels of accuracy encountered in archaeometric analyses]. For tin, the relative difference is nearly $20 \%$ and clearly higher than what would normally be accepted as uncertainty (Fig. 4). The above difference noted here could either reflect the instrumental error as, for example, reflected in the $20 \% \delta$ relative difference for the CRM BCR$691 \mathrm{D}$ (Table 3) or, in fact, a remaining effect of corrosion enrichment on the cleaned surface; the latter appears more likely based on the fact that when analysing certified reference materials, the pXRF values for tin were regularly lower than the certified values, not higher.

The relative error, defined here as the difference between the EPMA and the XRF1 values, increases as concentrations decrease. This is a general phenomenon widely known which can be noted also in our data here, from lead (EPMA value $\mathrm{c}$ $1.2 \mathrm{wt} \%$, relative error in XRF1 c $30 \%$ ) to nickel (EPMA
Table 4 Means of element concentrations measured in all 41 objects

\begin{tabular}{lrrr}
\hline & EPMA & XRF1 & XRF2 \\
\hline $\mathrm{Fe}$ & 0.16 & 1.55 & 2.82 \\
$\mathrm{Cu}$ & 90.51 & 86.82 & 77.37 \\
$\mathrm{Ni}$ & 0.07 & 0.24 & 0.26 \\
$\mathrm{Zn}$ & 0.00 & 0.44 & 0.49 \\
$\mathrm{As}$ & 0.16 & 0.30 & 0.39 \\
$\mathrm{Sn}$ & 7.50 & 8.84 & 13.23 \\
$\mathrm{Sb}$ & 0.09 & 0.18 & 0.28 \\
$\mathrm{~Pb}$ & 1.24 & 1.64 & 5.07 \\
$\mathrm{Mn}$ & 0.003 & na & 0.10 \\
\hline
\end{tabular}

Values in $\mathrm{wt} \%$ na not analysed

value $0.07 \mathrm{wt} \%$, XRF1 value $0.24 \mathrm{wt} \%$, more than three times the EPMA value).

The following discussion explores the possible reasons for the discrepancies of the results element by element. The two main possible reasons for errors in the $\mathrm{pXRF}$ analysis are limitations of the instrument (relatively high detection limits, errors in the calibration) and factors that affect the analysed surfaces, such as contamination through elements introduced from the environment during burial or the differential behaviour of the original metal components during corrosion, either through enrichment or selective leaching.

A noteworthy observation is that in the XRF1 measurements, the concentrations for all elements except copper are significantly higher than their equivalent EPMA values; for iron by a factor of 10 and for zinc even more: it is below the detection limit of the EPMA, estimated to about $0.02 \mathrm{wt} \%$, but is reported by the XRF1 as nearly half a percent $(0.44 \mathrm{wt} \%)$.

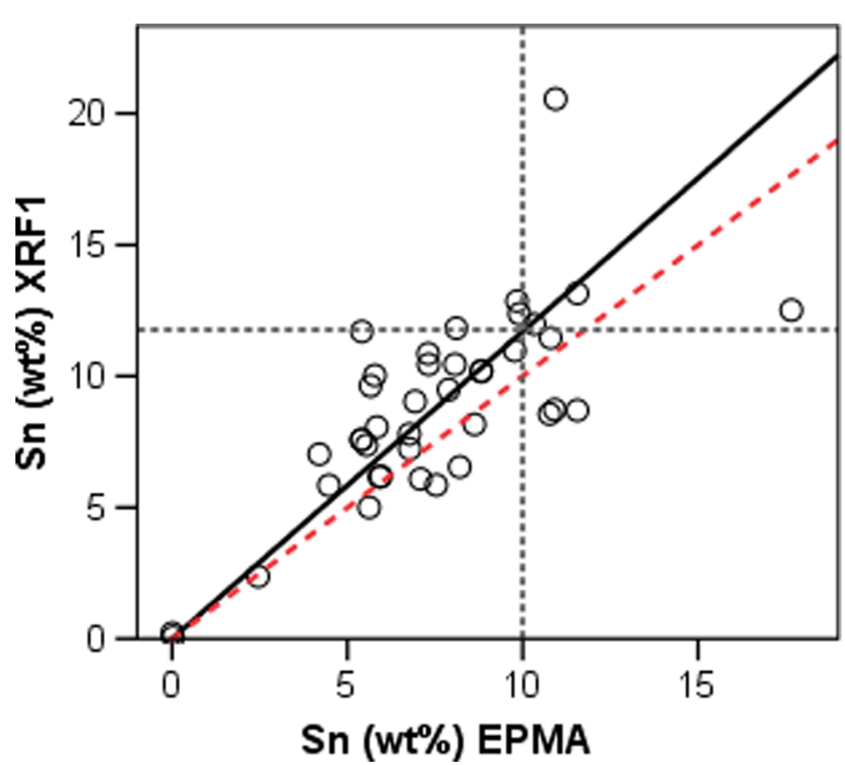

Fig. 4 Scatter plot of the EPMA and the pXRF analyses for the tin content; the black line indicates the fit line of the measured values; red dotted line indicates the ideal correlation for the two axes, i.e. $y=x$; the black dotted lines show the approximate $20 \%$ difference between the two protocols where an EPMA value of $10 \%$ could be $12 \%$ for the XRF1 
For some elements, this is further exacerbated in the XRF2 data, such as for lead (Fig. 5), but also for iron, antimony and tin. Other elements, such as nickel, zinc and arsenic, appear relatively unchanged in the XRF2 data compared to the XRF1 data. Only the copper concentrations are lower in the XRF1 data than that in the EPMA data, and again lower in the XRF2 data than that in the XRF1 data.

\section{Tin}

Tin is present in the sample with values approaching a $10 \%$ Sn bronze, i.e. the optimum bronze recipe which was also the par excellence copper-base alloy used in early Greece (Papadimitriou 2001, p. 597). Tin concentrations fall mostly between 5 and $10 \mathrm{wt} \%$ (EPMA mean value of $7.5 \mathrm{wt} \%$ ), a level where the XRF data should be accurate within a few percent relative. However, the mean surface values are significantly higher, reaching nearly $9 \mathrm{wt} \%$ in the cleaned surface (XRF1) and more than $13 \mathrm{wt} \%$ in the corroded surface (XRF2). Tin is known to be relatively immobile in most burial conditions compared to copper and therefore often found enriched in corroded bronze substrate layers. The enriched XRF2 data reflect this relative surface enrichment. However, Fig. 6 shows a significant amount of intergranular corrosion, which would result in some tin enrichment even if the artefact was cleaned to a depth where visually sound metal was exposed (the XRF1 protocol). It is, therefore, reasonable to assume that the relative enrichment between EPMA and XRF1, of around $20 \%$ of the absolute EPMA value, is at least partially due also to corrosion effects, despite analysing a visually sound metal surface.

\section{Lead}

A similar observation as for tin can be made for lead, even though, here, the enrichment from XRF1 to XRF2 is far higher. A characteristic property of lead is that it does not mix evenly with the rest of the elements present in the alloy (Staniaszek and Northover 1983). Instead, lead forms distinct prills which can create difficulties in accurately determining the lead content of bronze artefacts. During EPMA examination, only very small volumes in the order of a few cubic micrometres are analysed; depending on operator bias in selecting measurement spots, this can result in an over- or under-estimation of lead concentrations. In contrast, the pXRF analyses a surface area of about 1 or $2 \mathrm{~mm}$ across and, due to its higher excitation energy compared to the EPMA, reaches deeper into the artefact. Thus, the analysed volume is far greater and more likely to include a representative amount of lead. Nonetheless, a downside of the pXRF is its limited accuracy for lead which, as determined by CRMs analyses, was found on average overestimated by approximately $30 \%$ by the instrument (Fig. 7).

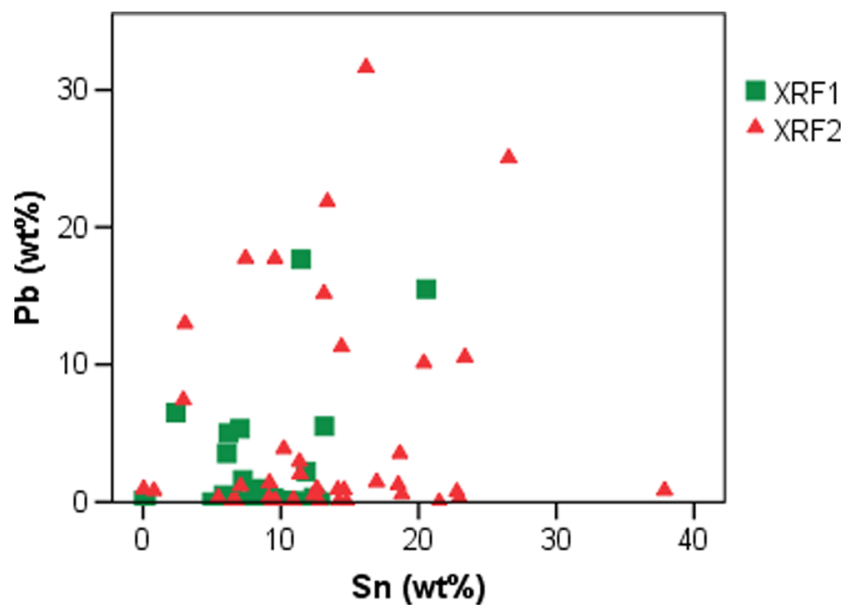

Fig. 5 Scatter plot of tin against lead values the XRF1 and XRF2 analyses; see above Fig. 3 for the same plot based on EPMA data. The lead values appear dramatically higher in this plot

Figure 8 illustrates a typical cross section through a lead-rich artefact. The area presented in the image is about half the size of the analytical spot of the pXRF instrument used here, while each individual EPMA analysis would not exceed a surface area in the image equal to about the size of the letter ' $\mathrm{O}$ ' in the caption 'BSECOMP'. During corrosion, however, lead-rich compounds enrich on or near the original surface of the artefact (see also Fig. 2, where the original artefact surface is marked by a thin layer of lead-rich material, resulting in a white line in the BSE image). Thus, XRF2 values for lead tend to be higher as a result of corrosion processes taking place on the objects' surface.

In addition to the overestimation of the lead content by the pXRF discussed above, occasionally, lead traces as analysed by the EPMA have not been caught up by the $\mathrm{pXRF}$ due to the latter's lower detection limit. The above is mostly seen not only for EPMA lead values between 0.01 and $0.04 \%$ but also with larger values up to $0.5 \% \mathrm{~Pb}$ as, for example, seen in the

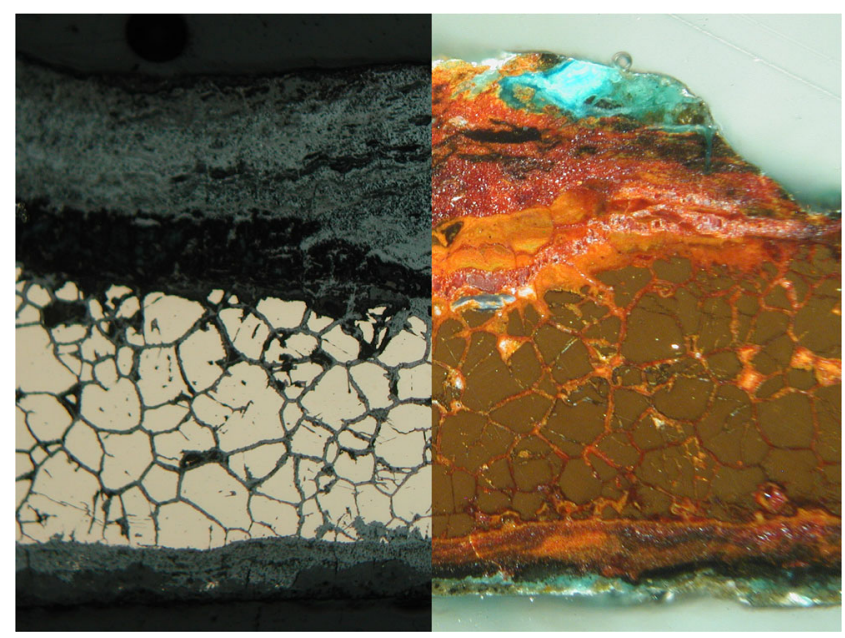

Fig. 6 Photomicrograph of sheet AE 480; corrosion products have affected the object throughout, outlining metallic grains. $100 \times$, image length $1.85 \mathrm{~mm}$, plane polarized light (PPL) (left) and XPL (right) 


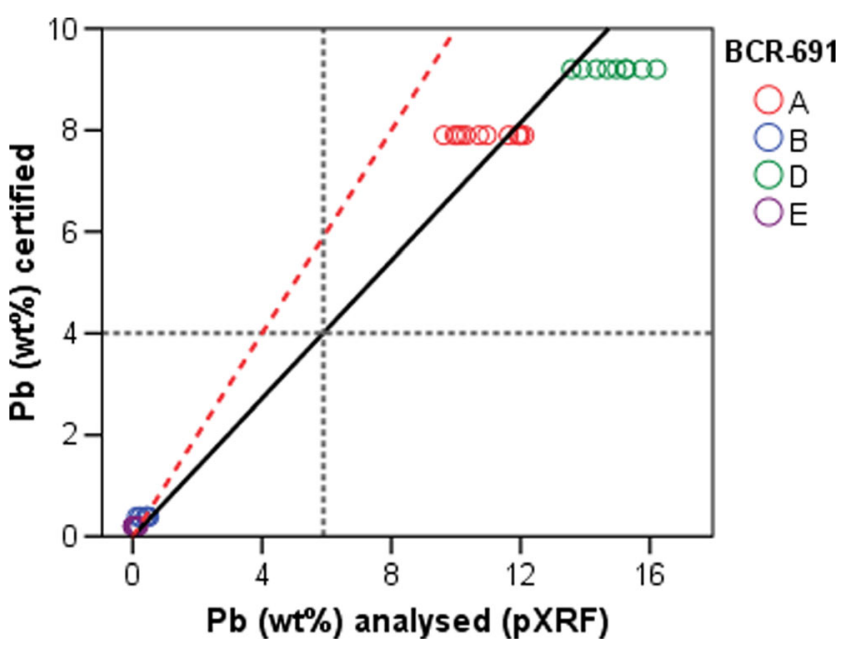

Fig. 7 Scatter plot of $\mathrm{Pb}$ analysed by XRF vs. certified values for the set of BCR-691 alloys; the black line indicates the fit line of the measured values; the red dotted line indicates the ideal correlation for the two axes, i.e. $y=x$; the grey dotted lines show that a lead value of $6 \%$ determined by $\mathrm{XRF}$ could be in reality as little as $4 \%$

case of AE 107 (Table 5). Samples with $<0.5 \%$ (EPMA) lead traces which were not detected during XRF1 have all shown a metal microstructure where minute lead inclusions are rarely seen (Fig. 9), as opposed to the large lead prills seen in AE 784 (Fig. 8) with $3 \%$ lead (EPMA).

Iron

Iron contents, as in the case of tin, tend to steadily increase from EPMA to XRF2 values. Iron is a common trace element in ancient copper, and the values found by EPMA are rather typical of Iron Age copper work as impurities from the raw material (Craddock 1976, p. 94, 1977, p. 115; Ingo et al. 2006, p. 517). Iron oxides typically occur in the corrosion layers of bronzes as a result of two factors, namely, the presence of the iron amount

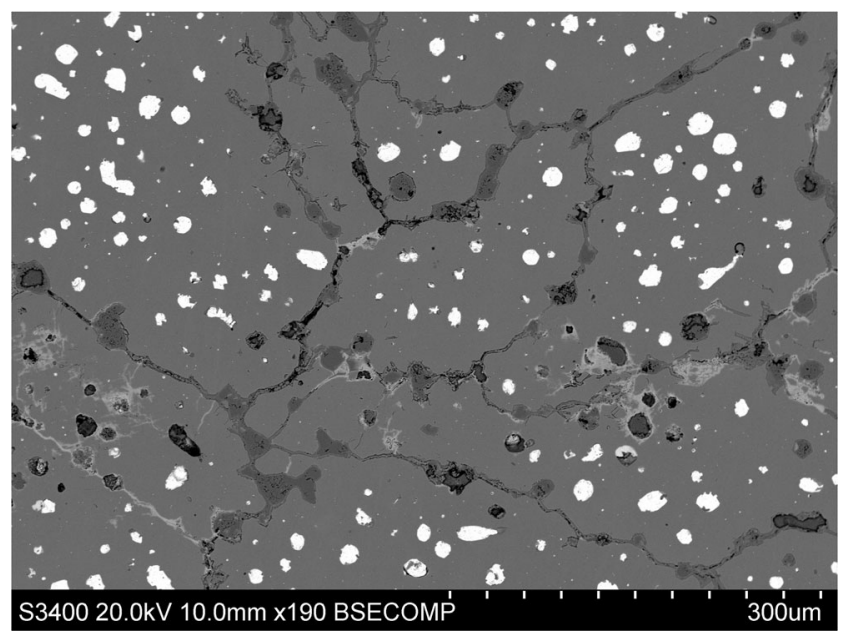

Fig. 8 Backscatter image of ring AE 784; lead prills (white) are widely visible in the microstructure. Note also the intergranular corrosion outlining the individual metal grains already in the copper/bronze metal as well as the presence of large amounts of iron in soil environments since iron is the fourth most abundant element in the Earth's crust (Jenkins 1989, p. 59; Ingo et al. 2006, p. 513). The near-doubling of iron concentrations in the XRF2 data compared to the XRF1 data is most likely due to such environmental contamination of the corrosion products during burial, either through absorption of iron ions or as mechanically incorporated soil particles. The presence of intergranular corrosion suggests that also the XRF1 values are affected by such environmental enrichment.

Zinc and nickel

Both zinc and nickel are common minor or trace elements in most copper ores. Nickel transfers almost completely during smelting into the metal phase, while zinc either evaporates or enters the metal phase (Pernicka 1990). The assemblage from Pherae is relatively low in both elements, with EPMA values for zinc below the detection limit of around $0.02 \mathrm{wt} \%$ and nickel at an average $0.07 \mathrm{wt} \%$. However, pXRF values are much higher for both elements, averaging between a quarter and half of $1 \%$ by weight. This cannot be readily explained by either environmental contamination nor by a corrosion-driven enrichment on the surface, even though zinc is a relatively mobile element most often present in soil environments with average soil concentrations of $50 \mu \mathrm{g} / \mathrm{g}(50 \mu \mathrm{pm})$, which can be enriched up to ten times depending on human or animal activity and the decomposition of remains (Jenkins 1989, pp. 57-58). Instead, it is most likely that these pXRF values are spurious, based on noise in the background, peak overlaps from the neighbouring very strong copper peaks or an over-interpretation of a weak real signal during the quantification process. Zinc in particular is prone to spurious signals even in wavelength-dispersive spectrometer analyses such as EPMA or WD-XRF, due to the proximity of the $\mathrm{Zn} \mathrm{K} \alpha$ line to the dominant copper $\mathrm{K} \beta$ peak. This problem is even stronger in energy-dispersive spectrometers with their lower peak resolution. The implications of an almost $5 \% \mathrm{Zn}$ bronze, such as the ring AE $838(4.5 \% \mathrm{Zn}$, XRF2 data), particularly for such an early period as the Geometric would have been of considerable importance, since early brasses and zinc-rich bronzes in Greece (typically before the Roman period and the first century B.C.) are quite rare (Craddock 1978, p. 1, 1998). Nonetheless, the zinc content as measured during XRF1 for the same object (AE 838) is only $0.1 \%$, i.e. much closer to the EPMA data, demonstrating that the surface analysis (XRF2) may not be reliable even when it comes to the basic identification of the alloy type. In total, six objects were found with pXRF values for zinc of more than $1 \%$ by weight, while on the basis of EPMA results, the entire assemblage has to be considered zinc-free. Consequently, the pXRF data for zinc have to be treated very critically before proceeding to any definite conclusions regarding the type of copper alloy. 
Table 5 Summary table for the lead content (wt\%) as analysed in the three protocols

\begin{tabular}{|c|c|c|c|c|c|c|c|}
\hline \multicolumn{8}{|l|}{$\mathrm{Pb}(\mathrm{wt} \%)$} \\
\hline Sample & EPMA & XRF1 & XRF2 & Sample & EPMA & XRF1 & XRF2 \\
\hline BE 45741 & n.d. & n.d. & n.d. & AE 827 & 0.17 & n.d. & 0.51 \\
\hline 1309 & n.d. & n.d. & 0.07 & AE 289 & 0.24 & 0.13 & 0.95 \\
\hline AE 838 & n.d. & n.d. & n.d. & AE 929 & 0.33 & n.d. & 1.27 \\
\hline M 1217.1 & n.d. & 0.04 & 1.16 & $\mathrm{AE} 97$ & 0.33 & n.d. & n.d. \\
\hline M 1217.2 & n.d. & n.d. & 1.40 & 1308 & 0.38 & 0.14 & 0.82 \\
\hline M 8100 & n.d. & n.d. & 0.11 & M 495 & 0.43 & 0.50 & 2.03 \\
\hline AE 666 & n.d. & n.d. & 0.10 & M 3367.1 & 0.50 & 0.30 & 0.88 \\
\hline M 1844 & 0.01 & n.d. & n.d. & AE 107 & 0.50 & n.d. & 1.46 \\
\hline AE 37 & 0.02 & n.d. & 0.13 & AE 899 & 0.57 & 0.16 & 0.90 \\
\hline AE 760 & 0.02 & 0.07 & 0.04 & M 3367.2 & 0.61 & 0.34 & 17.72 \\
\hline M 3234 & 0.03 & n.d. & 0.28 & M 1739.1 & 0.89 & 0.95 & 3.54 \\
\hline M 3234 & 0.03 & n.d. & 0.30 & AE 98 & 0.99 & 0.03 & 2.93 \\
\hline AE 113 & 0.04 & n.d. & n.d. & M 1314.1 & 1.66 & 1.61 & 7.44 \\
\hline M 1739.2 & 0.04 & 0.31 & 0.56 & AE 564 & 1.98 & 5.02 & 15.19 \\
\hline AE 624 & 0.06 & 0.04 & 0.74 & $\mathrm{AE} 459$ & 2.44 & 2.22 & 10.54 \\
\hline AE 606 & 0.07 & 0.96 & 3.88 & M 1314.2 & 2.79 & 3.55 & 17.76 \\
\hline AE 810 & 0.08 & 0.05 & 0.31 & AE 784 & 3.00 & 5.52 & 21.85 \\
\hline AE 103 & 0.09 & n.d. & 0.98 & $\mathrm{AE} 34$ & 5.86 & 5.35 & 11.29 \\
\hline M 1739.3 & 0.10 & n.d. & 0.85 & AE 507 & 7.40 & 15.51 & 31.62 \\
\hline AE 480 & 0.12 & 0.33 & 10.12 & 1310 & 8.21 & 6.52 & 13.00 \\
\hline AE 827 & 0.17 & n.d. & 0.51 & AE 506 & 9.49 & 17.68 & 25.05 \\
\hline
\end{tabular}

n.d. not detected

\section{Other trace elements}

Values for the rest of the trace elements such as arsenic and antimony tend to be higher in surface analyses (XRF2) as well as on clean metal analyses with the pXRF (XRF1) relative to the values detected with the EPMA. The levels for antimony with an average of 0.09 and for arsenic with an average of $0.16 \%$ and a maximum value of $0.64 \%$ As suggest their

Fig. 9 Photomicrographs of AE 97, 103, 107 and 827 whose traces of lead were not detected during XRF1 analyses; in all samples, a metal grain structure with several sulphide inclusions (grey) but very few minute lead ones (black) is visible; PPL, $500 \times$, images length $35 \mu \mathrm{m}$
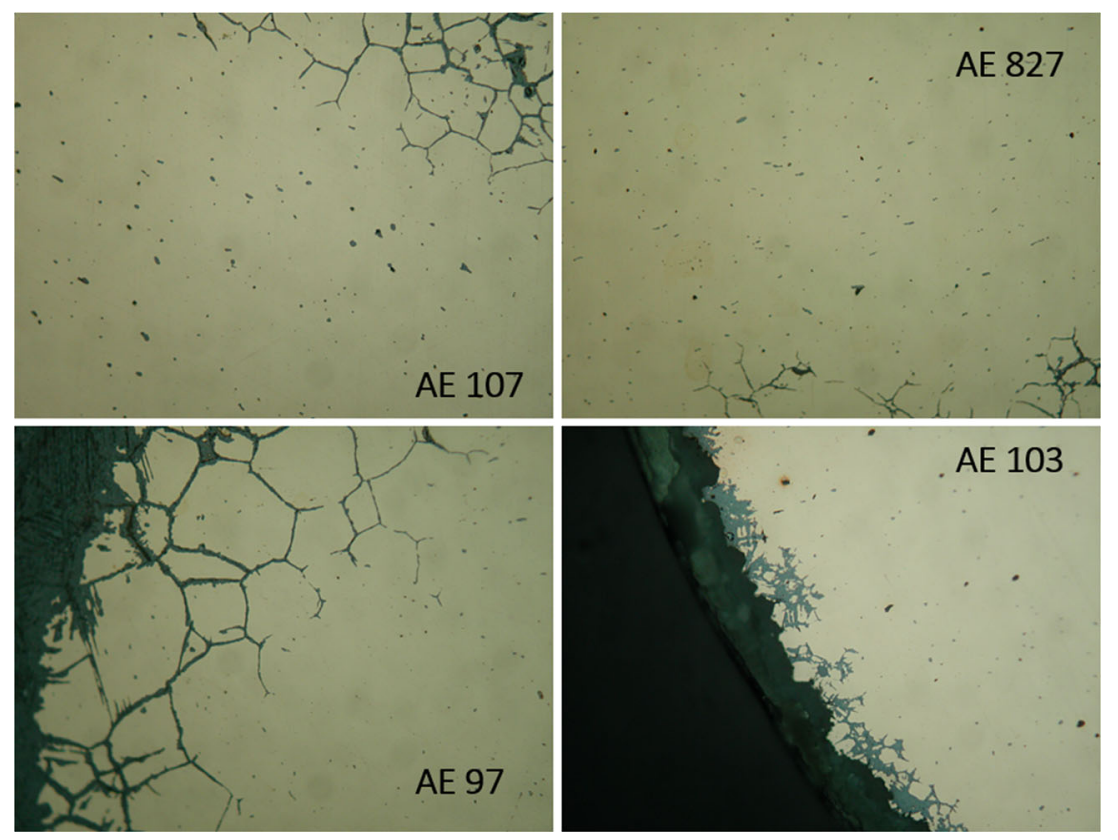


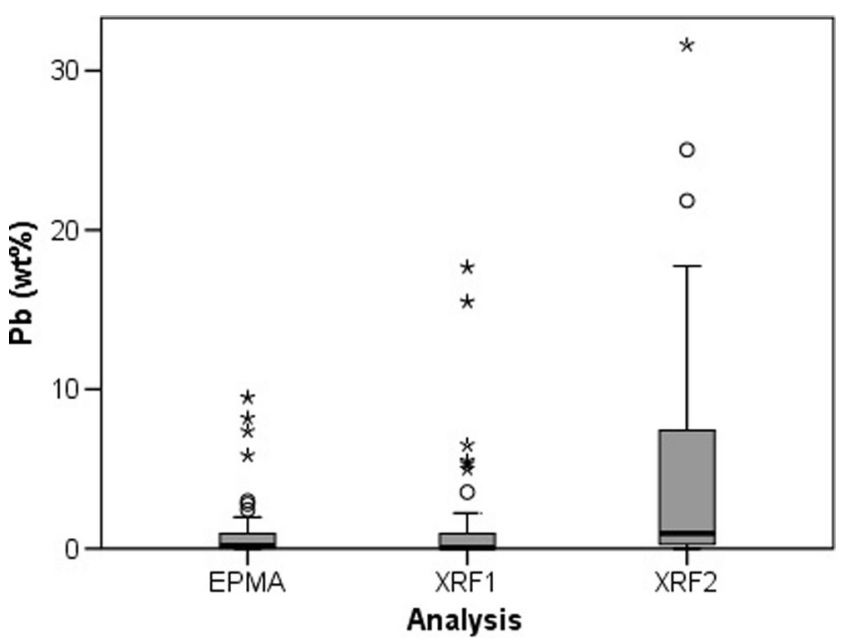

Fig. 10 Five-point box plot for lead values in all three analytical approaches

presence as an impurity from the copper ores. The apparent profile in the increase from the EPMA data to the pXRF data, however, differs for the two elements; for arsenic, the main increase is from the EPMA to the pXRF values, with little if any further increase from XRF1 to XRF2. This suggests that the pXRF data is mostly spurious and a result of the instrument's performance. In contrast, the antimony data increases significantly from XRF1 to XRF2, suggesting a real enrichment of antimony in the corrosion products which has also been observed in a separate study on corrosion behaviour of archaeological metal (Rehren and Prange 1998). Despite the lower absolute concentrations of antimony compared to arsenic, we trust the XRF data for antimony more, due to its better excitation characteristics and fewer peak overlap problems for the $\mathrm{Sb} \mathrm{K} \alpha$ peak compared to the arsenic $\mathrm{K} \alpha$ peak and its overlap with the lead $\mathrm{M} \alpha$ peak.

Traces of manganese were found during EPMA analysis with both mean and median values of $0.003 \%$ and a maximum of $0.1 \% \mathrm{Mn}$. Manganese was not analysed during XRF1 analysis, but it was found during surface analysis (XRF2) with average and maximum values of 0.1 and $0.23 \% \mathrm{Mn}$, respectively. This increase in the manganese content of several times of the EPMA values has to be attributed, as in the case of iron, to the surface enrichment as a result of corrosion processes which tend to increase surface trace element concentration and environmental contamination from the soil system as well (Jenkins 1989, p. 59).

\section{Discussion}

The comparison between EPMA and pXRF results has raised a number of issues regarding data quality, instrument comparability and surface analysis reliability. This contributes to the discussion of the relative merit of invasive and surface analyses, as well as on the importance to understand data quality for any method used, for an enhanced understanding of ancient copper-based assemblages. Consequently, the interpretation of any surface $\mathrm{pXRF}$ results, either on scraped or intact surfaces, needs to take into consideration possible surface enrichment during long-term burial in certain elements which depends on the compositions of the soil and the objects themselves. For instance, iron, manganese and zinc which are present in most soil environments could be enhanced further by human activity (Jenkins 1989). These elements have all been detected in higher levels during surface pXRF analysis but do not reflect the original composition of the alloys used as analysed with EPMA.

In addition, phenomena of differential corrosion of copper or tin in ancient bronzes and preferential depletion of the main alloy components, i.e. copper and/or tin in regard to the present analyses, have to be addressed since they immediately affect the quality of surface pXRF results by providing (mostly) higher values for tin (Scott 1985; Meeks 1986, p. 137). Depending on which layer of the corroded surface is analysed, either tin or copper can be significantly enriched. Moreover, lead values also tend to increase in surface analyses (Fig. 10) but not in a consistent or predictable manner (see Table 5). Significantly, even surfaces apparently cleaned until solid metal is exposed can still include deep-rooted intergranular corrosion, resulting in distorted results. Overall, the above evidence points to the importance of sound metal analysis (EPMA or XRF1) not only for the minor and trace elements concentrations but for an accurate determination of the alloys' nature as well.

In addition to corrosion processes and soil contamination, the detection limit of the pXRF has also to be considered, particularly when dealing with elements at impurity levels. This can be illustrated by looking at several XRF1 analyses which did not detect any lead content, even though the EPMA detected lead due to its lower detection limit for this element (as seen in Table 5).

\section{Conclusion}

The use of pXRF is often the only way for archaeologists and conservators to obtain analytical results from artefacts held in major collections, where invasive sampling is not an option (e.g. Charalambous et al. 2014). As shown by the analytical results discussed here, all pXRF data obtained have to be interpreted with caution. The instrumental limitations of such portable equipment as well as the issues relating to the inherent changes in composition that affect ancient surfaces have to be taken into consideration. Importantly, even though most elements other than copper generally appear too high in $\mathrm{pXRF}$ analyses, the assessment of reliability has to be done for each 
element separately and individually, as each element will have its own specific problems. Based on the data presented here, it is argued that it is possible to obtain reasonable quality data regarding the nature and approximate concentrations of the main components present in copper-based alloys such as tin and lead, provided that a metallic surface large enough for the spot of the instrument can be exposed (approx. 1-3 mm). Even though absolute values may vary for the major elements between the pXRF and EPMA-WDS, trends and patterns in the results can be in agreement, providing thus some information on the nature of the alloys used. For trace elements, though, pXRF data can be misleading and their interpretation has to consider surface corrosion phenomena in addition to the instrument's specifications. This is particularly true for corroded surface (see XRF2), for which data obtained in this study appears to be generally not reliable or useful.

Notwithstanding, in most objects analysed here even by looking at XRF2 results, it is safe to argue that all objects are copper-based (as already indicated by their green corrosion surfaces) and that tin and occasionally lead are the main alloying agents, even if it is not possible to give an accurate estimation of the original alloy composition. Furthermore, XRF1 results on the objects' scraped surfaces are to be better trusted and taken as relatively more realistic in distinguishing between bronze and leaded bronze objects. Accordingly, on the bases of the pXRF data, it is possible to sort the assemblage into rough groupings of low, medium and high concentrations for the major elements. For such a categorization, XRF1 values are much closer to the EPMA values and, thus, more reliable.

For most elements in the periodic table up to about arsenic, EPMA analysis based on WDS provides more accurate results with much lower detection limits than the $\mathrm{pXRF}$, while the latter is more sensitive for heavier elements due to its higher excitation energy. In any case, analyses of sound metal exposed by an experienced conservator should be clearly preferred over corroded surfaces since, as shown here, the former produces results much closer to the original alloy compositions of ancient metal objects. The benefits of analysing sound metal (XRF1) as opposed to the corroded surface (XRF2) are unambiguous.

Despite the above limitations, analysis of ancient metal objects with portable and handheld XRF instruments is and will continue to be popular not only due to its non-invasive nature but also because it is much less time consuming and more cost effective which makes it widely applicable in archaeological research.

Acknowledgments This study would not have been possible without the invaluable help of Eleni Asderaki, Honorary Head of the Conservation Department of 13th EPCA, Volos, and Kevin Reeves, Wolfson Archaeological Science Laboratories, UCL Institute of Archaeology, who we warmly thank. We also wish to acknowledge Dr. Arg. Intzesiloglou and P. Arachoviti, 13th EPCA, Volos, for providing access to material and their support during analyses, and Nikos Zacharias, University of Peloponnese, for organising the 3rd Symposium on Archaeological Research and New Technologies where preliminary results of the study were presented.

Open Access This article is distributed under the terms of the Creative Commons Attribution License which permits any use, distribution, and reproduction in any medium, provided the original author(s) and the source are credited.

\section{References}

Angelini E, Grassini S, Corbellini S, Ingo GM, De Caro T, Plescia P, Riccucci C, Bianco A, Agostini S (2006) Potentialities of XRF and EIS portable instruments for the characterisation of ancient artefacts. Appl Phys A Mater Sci Process 83:643-649

Béquignon Y (1937) Recherches archéologiques à Phères de Thessalie. Les Belles Lettres, Paris

Bouzek J (1997) Greece, Anatolia and Europe: cultural interrelations during the Early Iron Age. Stud Mediterr Archaeol 122

Caley ER (1964) Analysis of ancient metals. Pergamon Press, London

Cesareo R, Bustamante A, Fabian J, Calza C, Dos Anjos M, Lopes RT, Alva W, Seclen M (2011) Portable equipment for a non-destructive analysis of pre-Columbian metal artefacts from the Royal Tombs of Sipán by energy-dispersive X-ray fluorescence spectrometry. X-Ray Spectrom 40(1):37-46

Charalambous A, Kassianidou V, Papassavas G (2014) A compositional study of Cypriot bronzes dating to the Early Iron Age using portable X-ray fluorescence spectrometry (pXRF). J Archaeol Sci 46:205-216

Charles JA (1973) Heterogeneity in metals. Archaeometry 15:105-114

Craddock PT (1976) The composition of the copper alloys used by the Greek, Etruscan and Roman civilizations: 1. The Greeks before the Archaic Period. J Archaeol Sci 3:93-113

Craddock PT (1977) The composition of the copper alloys used by the Greek, Etruscan and Roman civilizations: 2. The Archaic, Classical and Hellenistic Greeks. J Archaeol Sci 4:103-123

Craddock PT (1978) The composition of the copper alloys used by the Greek, Etruscan and Roman civilizations: 3. The origins and early use of brass. J Archaeol Sci 5:1-16

Craddock PT (1998) Zinc in classical antiquity. In: Craddock PT (ed) 2000 years of zinc and brass. British Museum, London, pp 1-6

Dussubieux L, Deraisme A, Frot G, Stevenson C, Creech A, Bienvenu Y (2008) LA-ICP-MS, SEM-EDS and EPMA analysis of eastern North American copper-based artefacts: impact of corrosion and heterogeneity of the reliability of the LA-ICP-MS compositional results. Archaeometry 50(4):643-657

Franceschi E, Macciò L, Rosa L (1998) The corrosion of metallic artifacts within different environments: archaeological objects and laboratory simulations. In: Mourey W, Robbiola L (eds) Metal 98. James and James, London, pp 92-93

Hein A, Tsokalidou A, Iliopoulos I, Mommsen H, Buxeda i Garrigos J, Montana G, Kilikoglou V (2002) Standardisation of elemental analytical techniques applied to provenance studies of archaeological ceramics: an inter-laboratory calibration study. Analyst 127:542-553

Henderson J, Manti P (2008) Improving access to collections for sampling. In: Saunders D, Townsend JH, Woodcock S (eds) Conservation and access. Contributions to the London Congress, 15-19 September 2008. ICC, London, pp 115-119

Ingo GM, De Caro T, Riccucci C, Angelini E, Grassini S, Balbi S, Bernardini P, Salvi D, Bousselmi L, Çilingiroglu A, Gener M, Al Jarrah O, Khosroff S, Mahdjoub Z, Al Saad Z, El-Saddik W, Vassiliou P (2006) Large scale investigation of chemical 
composition, structure and corrosion mechanism of bronze archaeological artefacts from Mediterranean basin. Appl Phys A Mater Sci Process 83(4):513-520

Jenkins DA (1989) Trace element geochemistry in archaeological sites. Environ Geochem Health 11(2):57-62

Kantarelou V, Karydas AG, Zarkadas C, Giannoulaki M, Argyropoulos V (2007) Micro-XRF analysis of high tin bronze mirrors at the Museum of Ancient Messene in Greece. In: Argyropoulos V, Hein A, Abdel-Harith M (eds) Strategies for saving our cultural heritage. Athens, TEI of Athens, pp 93-99

Karydas AG (2007) Application of a portable XRF spectrometer for the non-invasive analysis of museum metal artefacts. Ann Chim 97: 419-432

Kilian K (1975) Fibeln in Thessalien von der mykenischen bis zur archaischen Zeit. Beck, München

Kilian-Dirlmeier I (1985) Fremde Weihungen in griechischen Heiligtümern vom 8. bis zum Beginn des 7. Jahrhunderts v. Chr. Jahrbuch des Römisch-germanischen Zentralmuseums, Mainz, 32, $215-54$

Mangou H, Ioannou PV (1998) On the chemical composition of Prehistoric Greek copper-based artefacts from Crete. BSA 93:91-102

Martinón-Torres M, Li XJ, Bevan A, Xia Y, Zhao K, Rehren Th (2012) Forty thousand arms for a single emperor: from chemical data to the labor organization behind the bronze arrows of the Terracotta Army. J Archaeol Method Theory 19:1-29

Meeks ND (1986) Tin-rich surfaces on bronze - some experimental and archaeological considerations. Archaeometry 28(2):133-162

Mezzi A, De Caro T, Riccucci C, Parisi EI, Faraldi F, Vassiliou P, Grassini S (2012) Analytical methodologies for the investigation of soilinduced degradation of $\mathrm{Cu}$-based archaeological artefacts. Surf Interface Anal 44(8):953-957

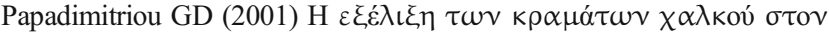

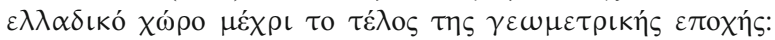

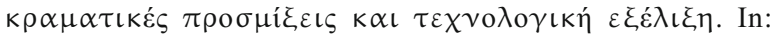
Bassiakos Y, Aloupi E, Facorellis Y (eds) Archaeometry issues in
Greek prehistory and antiquity. Athens: Hellenic Society of Archaeometry, Soc Messenian Archaeol Stud 587-608

Pernicka E (1990) Gewinnung und Verbreitung der Metalle in prähistorischer Zeit. Jahrb Römisch-Germanischen Zentralmuseums Mainz 37:21-129

Pernicka E, Begemann F, Schmitt-Strecker S, Grimanis AP (1990) On the composition of metal artefacts from Poliochni on Lemnos. Oxf J Archaeol 9:263-297

Rehren Th, Prange M (1998) Lead metal and patina: a comparison. In: Rehren Th, Hauptmann A, Muhly J (eds) Metallurgica Antiqua, Deutsches Bergbau-Museum, Bochum, pp 183-196

Scott DA (1985) Periodic corrosion phenomena in bronze antiquities. Stud Conserv 30(2):49-57

Scott DA (1991) Metallography and microstructure of ancient and historic metals. The Getty Conservation Institute, LA

Scott DA (2002) Copper and bronze in art: corrosion, colorants, conservation. The Getty Conservation Institute, LA

Shugar AN (2013) Portable X-ray fluorescence and archaeology: limitations of the instrument and suggested methods to achieve desired results. In: Armitage RA, Burton JH (eds) Archaeological chemistry VIII. American Chemical Society, Washington D.C, pp 173-193

Shugar AN, Mass JL (eds) (2012) Handheld XRF for art and archaeology. Leuven University Press, Leuven

Staniaszek BEP, Northover JP (1983) The properties of leaded bronze alloys. In: Spinall AA, Warren SE (eds) The Proceedings of the 22nd Symposium on Archaeometry, 30 March-3 April 1982. Bradford, W. Yorks: Schools of Physics and Archaeological Sciences, University of Bradford, 262-272

Tite MS, Merriman N, Rehren Th, Schadla-Hall T, Walker Tubb K (2002) Invasive sampling vs. object integrity. Pap Inst Archaeol 13:1-5

Tylecote RF, Ghaznavi HA, Boydell PJ (1977) Partitioning of trace elements between ores, fluxes, slags and metal during the smelting of copper. J Archaeol Sci 4:305-333

Vokotopoulou I (1986) Vitsa: the cemeteries of a Molossian settlement (in Greek). TAP, Athens

Vokotopoulou I (1990) The tombs of Aeneia (in Greek). TAP, Athens 